\title{
Combustors with Low Emission Levels for Aero Gas Turbine Engines
}

\author{
N. GueLLOUH ${ }^{1}$, Z. SZAMOSI ${ }^{2}$, Z. SimENFALVI ${ }^{3}$ \\ Institute of Energy Engineering and Chemical Machinery, Faculty of Mechanical Engineering and Informatics, \\ University of Miskolc \\ E-mail: noureddine.guellouh94@gmail.com¹, vegyszam@uni-miskolc.hu², simenfalvi@uni-miskolc.hu
}

\begin{abstract}
The aircrafts are responsible for emitting several types of pollutants, especially the pollutants in the form of $\mathrm{NO}_{X}, \mathrm{CO}_{2}, \mathrm{CO}, \mathrm{UHC}, \mathrm{SO}_{X}$ and Particulate Matter PM (smoke/soot). The impact of aviation emissions on the global is well known, where these emissions modify the chemical and microphysical properties of the atmosphere resulting in changes of earth's climate system, which can ultimate in critical changes in our planet fragile ecosystem, also the pollutants produced by aircraft engines cause many health problems. This is why the International Civil Aviation Organisation (ICAO) is seriously seeking to control the emission levels by issuing new standards during the successive meetings of the Committee on Aviation Environmental Protection CAEP (CAEP/01 in 1986, CAEP/2, $C A E P / 4, C A E P / 6, C A E P / 8$, etc). The new regulations include more stringent standards aimed to reduce emission levels, this led to increased interest in low emission technologies. In this paper, a comprehensive review of low emissions combustion technologies for modern aero gas turbines is represented. The current low emission technologies include the high Technologies Readiness Level (TRL) including RQL, TAPS, DAC and LDI. Also, there are advanced technologies at lower TRL including LPP, ASC and VGC.
\end{abstract}

Keywords: combustion, technology, low emissions, rich burn, lean burn.

\section{Introduction}

Some people may think that most aviation research is focused only on how to produce larger planes with higher speeds and different shapes, but this is not right, where most researchers and scientists focus on how to control emission levels. The aircrafts are responsible for emitting several types of pollutants, especially the pollutants in the form of Nitrogen Oxides $\mathrm{NO}_{\mathrm{x}}$ (comprising $\mathrm{NO}$ and $\mathrm{NO}_{2}$ ) which are one of the most toxic pollutants in the atmosphere and are well known as a destroyer of the ozone layer and a precursor of the acid rain [1], where $\mathrm{NO}_{\mathrm{x}}$ can cause problems to the atmosphere, such as smog and ozone in the lower troposphere and decreased ozone in the stratosphere. Also the $\mathrm{NO}_{\mathrm{X}}$ can cause health problems such as lung irritation and lower resistance to respiratory infections [2]. The other pollutants have also very bad effects on our health. For example, the Carbon dioxide $\mathrm{CO}_{2}$ and Carbon monoxide $\mathrm{CO}$ which cause cardiovascular problems, especially in those persons with heart conditions. Unburned Hydrocarbons UHC lead to visual disorders, respiratory problems and memory impairment. Sulphur oxides $\left(\mathrm{SO}_{\mathrm{x}}\right)$ are other serious pollutants, where exposure to sulphur dioxide in the ambient air has been associated with reduced lung function, increased incidence of respiratory 
symptoms and diseases, irritation of the eyes, nose, and throat, and premature mortality [3]. Aggravation of respiratory and cardiovascular disease, altered respiratory defense mechanisms and changes to lung tissues and structure are some of the effects resulting from another pollutants in the form of Particulate Matter PM that contains mainly smoke/soot.

A significant development has been achieved, where over the past 40-50 years the aviation industry has been capable of reducing fuel consumption by $70 \%$ while also limiting noise and reducing gaseous CO and HC emissions by approximately 50 and 90\%, respectively [4]. This development was the result of technology improvement in materials and cooling that enable engine to operate at higher Overall Pressure Rations (OPRs) and Turbine Entry Temperatures (TETs) to increase thermal efficiency which in turn reduces the engine specific fuel consumption (SFC) for economic benefit. Until 1970s, when larger OPR engines were developed less attention was paid to $\mathrm{NO}_{\mathrm{x}}$ emissions until serious concerns were raised by the general public on the effects of $\mathrm{NO}_{\mathrm{x}}$ on human health and climate [5]. The stringent international standards aimed to reduce emission levels led to increased interest in low emission technologies. Since the adoption of the International Civil Aviation Organization (ICAO) the CAEP/1 standard or ICAO 1986 standard, new low emission technologies have been created and developed to comply with the new regulations issued by the ICAO during the subsequent meetings of this organization, where the new standards are becoming stricter.

\section{Environmental concerns and restrictions}

With such an increase in fleet and operations, an increase in environmental concerns is also to be expected and even more stringent throughout the years to come. Aircraft engines currently run on fossil-fuel which it combustion emit various pollutants to the atmosphere, affecting local and regional air quality, as well as affecting its cleanest regions at high altitude under cruise conditions, as presented in Figure 1. Such emissions modify the chemical and microphysical properties of the atmosphere resulting in changes of earth's climate system, which can ultimate in critical changes in our planet fragile ecosystem [6].

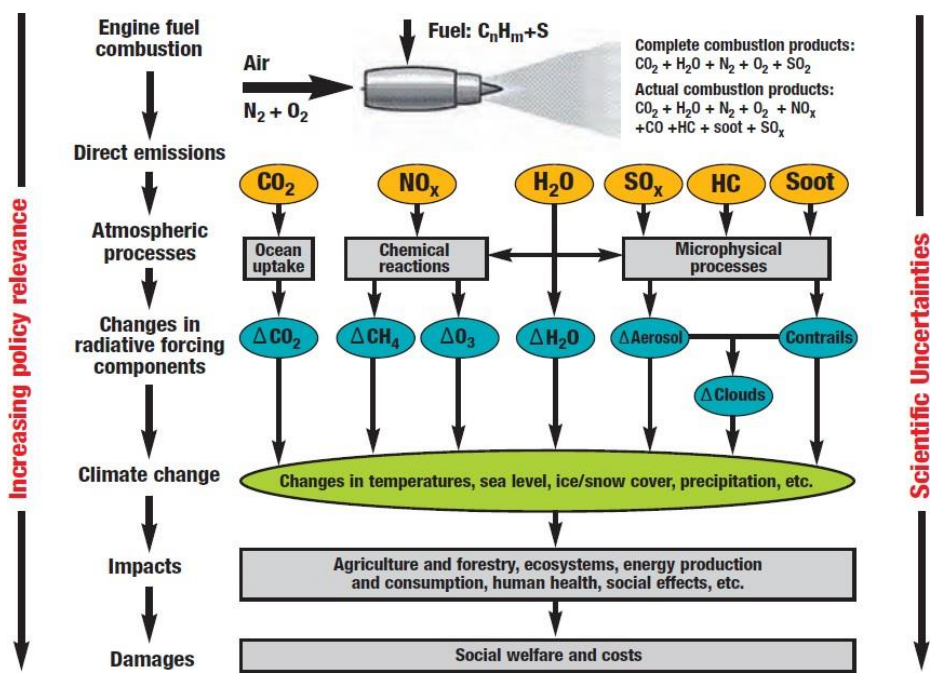

Figure 1. Schematic representation of aircraft emissions and their causal linkages with potential climate and social welfare impacts [9]. 
To reduce pollutant emissions by the aerospace industry the Committee on Aviation Environmental Protection CAEP, which is responsible for formulating new standards in aircraft noise and emissions regulations, established limits addressing local air quality in the vicinity of the airports based on a Landing- takeoff LTO cycle analysis [6]. The standards for smoke, CO and UHC remain unchanged in subsequent review. As $\mathrm{NO}_{\mathrm{X}}$ has been considered as a primary issue, ICAO adopted a more stringent standard for $\mathrm{NO}_{\mathrm{x}}$ emissions at the 2nd, 4th, 6th and 8th meetings of CAEP [5] (Figure 2). In recent years, the focus of CAEP has been expanded to develop global standards for $\mathrm{CO}_{2}$ emission and nonvolatile particulate matter standard (nvPM). Consequently, during the CAEP/10 meeting in 2016, recommendations have been made for the two complementary new standards for the emissions. The $\mathrm{CO}_{2}$ standard will apply to subsonic aircraft of new type design starting in 2020, and to those in production in 2023 [7]. Additionally, attention is also been accorded to address the impact of emissions at high altitude (i.e. $\mathrm{NO}_{\mathrm{x}}$ at climb and cruise) [8].

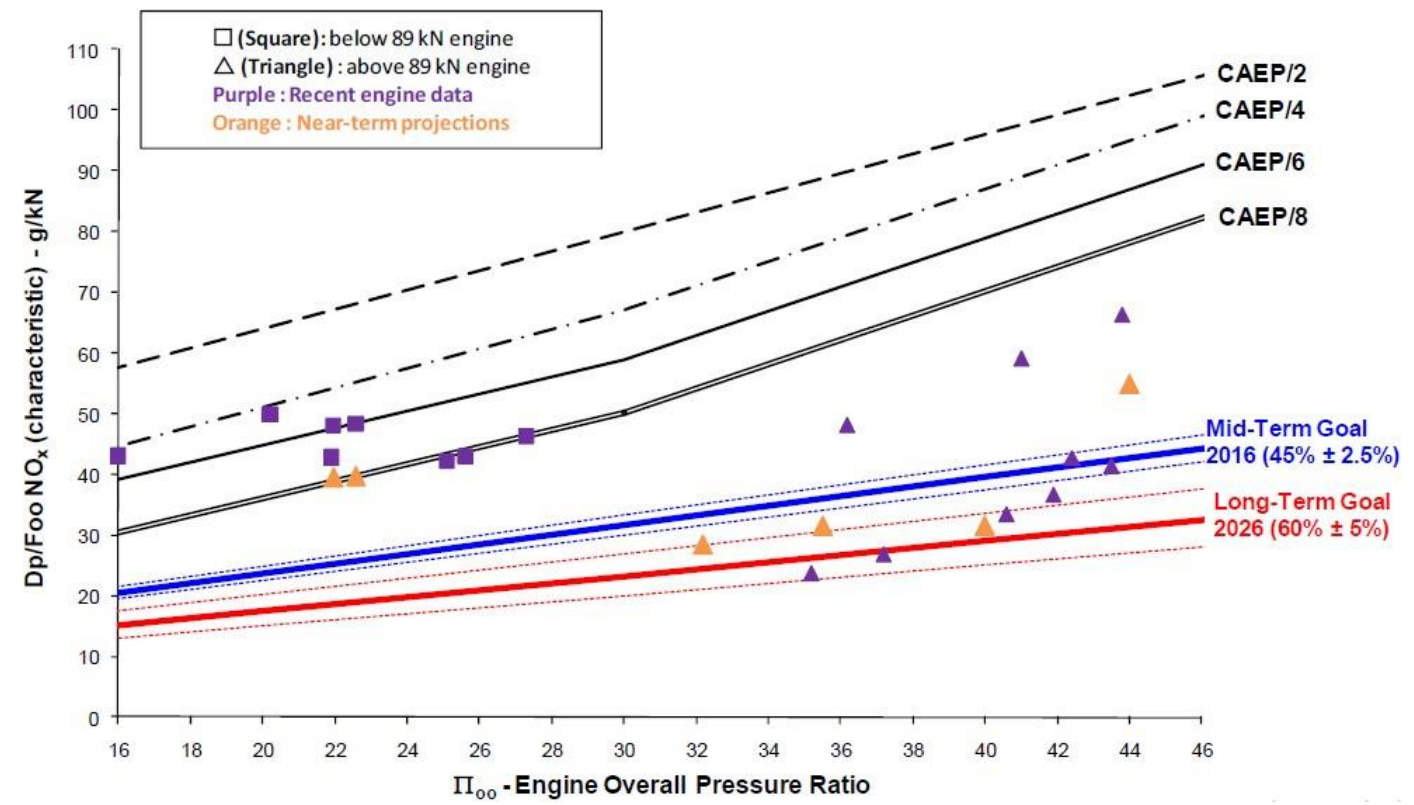

Figure 2. Aviation NOx emissions requirements according to ICAO standards [10].

\section{Modern combustion technologies with low emission levels}

The governmental regulations for gas turbine emissions are becoming increasingly more stringent. The demand for new improved designs with ultra-low pollutant emissions is rapidly moving to the forefront of combustor development [11]. Although emissions could be a focus when designing a typical low emissions combustor, the importance of other performance interacting with the emissions should be explored thoroughly. Therefore the performance should not be compromised when designing a low emission combustor. The interrelated combustor performance for design considerations is shown in Figure 3. 


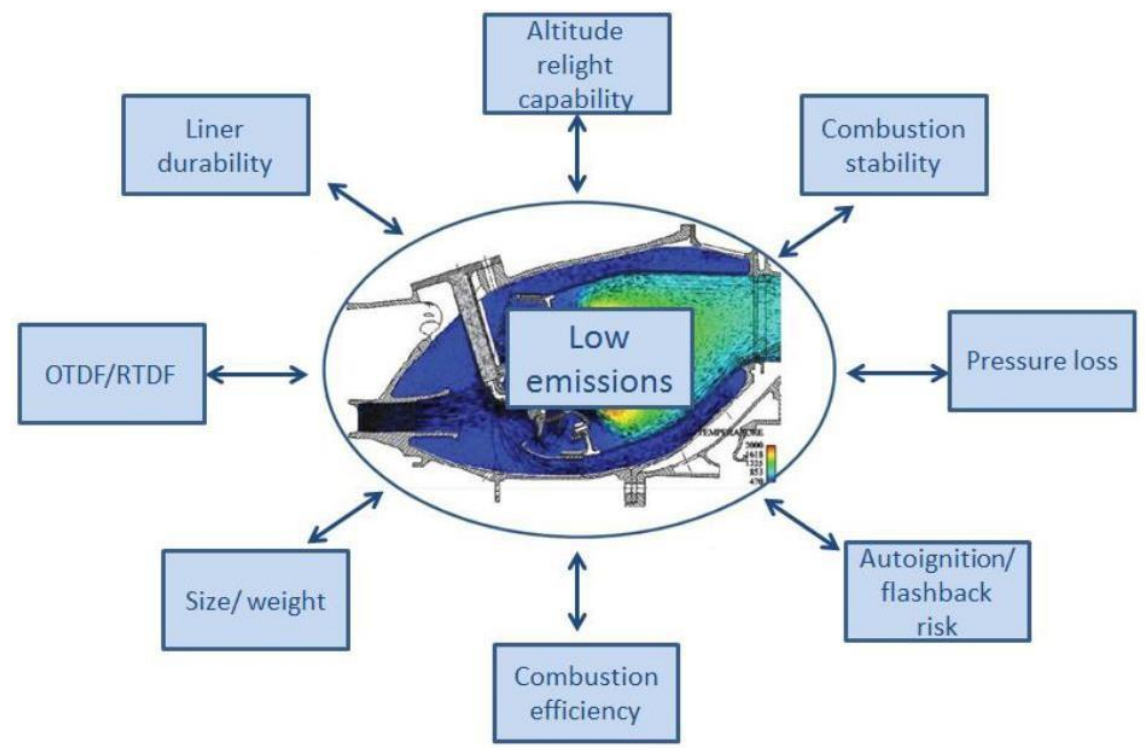

Figure 3. Interrelated combustor design considerations. (OTDF/RTDF Overall/Radial Temperature Distribution Factor) [5].

Safety is always the most important airworthiness criterion and there is no exception for low emissions combustors design perspective. The altitude-relight capability and avoidance of autoignition/flashback should be considered primarily during the early stage of the design. Stable combustion is critical as combustion instability could damage the hardware of the combustor and become a safety issue. Operability should be also considered as a high priority to ensure the combustor is capable of operating over a widerange of fuel-air ratios, (larger turndown ratio). The performance criteria such as combustion efficiency and pressure loss are always the key design considerations because the combustor design has to satisfy the whole engine requirement as SFC and total fuel consumption of the engine are proportional to the combustion efficiency. Pressure loss, as an important engine cycle parameter also affects the whole engine design, particularly for engine SFC. Size and weight are important for aero applications, particularly for small/medium aircraft. In order to meet the durability requirement, the component should be designed to ensure they are capable of operating over thousands of hours and flight cycles. The satisfactory downstream turbine thermal and life integrity should be achieved by improving the exit temperature distribution $[11,5]$.

\subsection{Rich-burn Quick-quench Lean-burn combustors (RQL)}

The Rich-Burn, Quick-Mix, Lean-Burn (RQL) combustor concept was introduced in 1980 as strategy to reduce oxides of nitrogen $\left(\mathrm{NO}_{\mathrm{X}}\right)$ emission from gas turbine engines. $\mathrm{RQL}$ combustor technology is of growing interest for stationary applications due to the attributes of more effectively processing fuels of complex composition, and processing fuels of varying composition [12]. In the 1990's the RQL concept was selected by the High Speed Research (HSR) program at NASA as a candidate for the reduction of oxides of nitrogen in engines for a High Speed Civil Transport (HSCT) in part because in aero-engine applications an RQL may be preferred over lean premixed prevaporized (LPP) options due to safety considerations and overall performance (e.g. stability) of the RQL throughout the duty cycle. Today, $\mathrm{RQL}$ technology is used in aero-engines deployed commercially by Pratt \& Whitney under the name 
TALON (Technology for Advanced Low NOx) [13,12]. This technology is becoming more important with the increasing international competition for fuels in general, and an increasing interest in liquefied natural gas, biomass fuels, and low calorific value gas [14]. The success of this low- $\mathrm{NO}_{\mathrm{X}}$ combustor strategy is dependent upon the links between the formation of $\mathrm{NO}_{\mathrm{x}}$, inlet air preheat temperature, and the mixing of the jet air and fuel-rich streams [13].

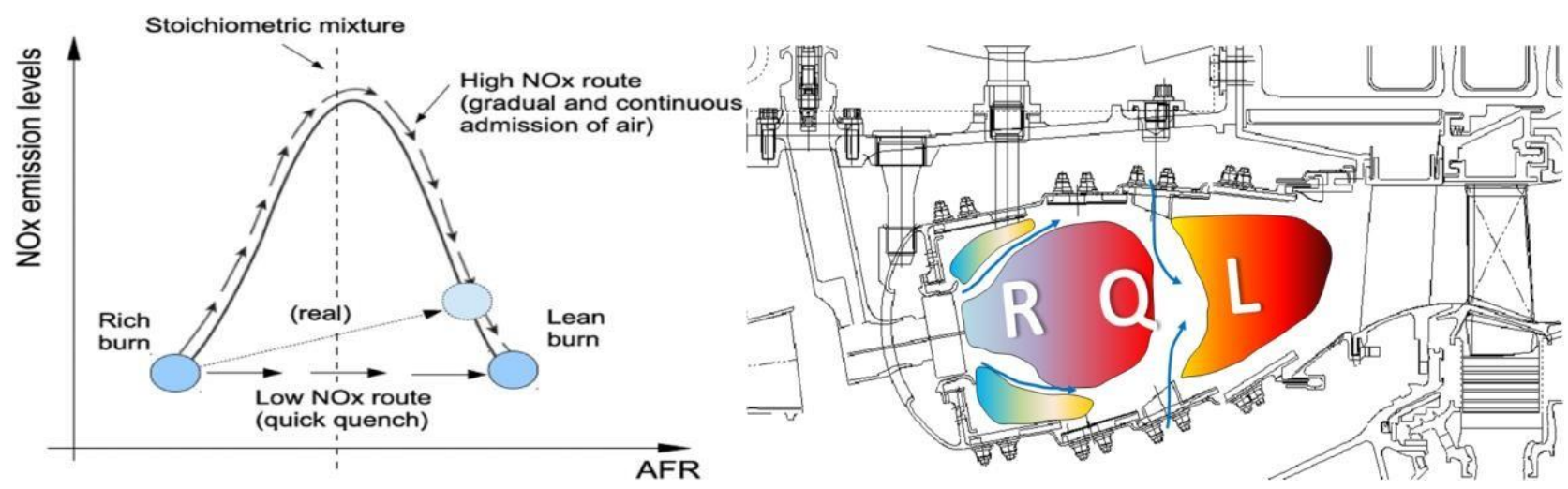

Figure 4. Rich-Quench-Lean combustor concept [17].

The RQL concept is predicated on the premise that the primary zone of a gas turbine combustor operates most effectively with rich mixture ratios [12]. This combustion technique is a special staged combustion technology, the first is a rich-burn stage, the middle is a quick-quench stage, and the last is a lean-burn stage[15] (Figure 4). The combustion is initiated by a fuel-rich mixture in the primary zone with equivalence ratio normally 1.2-1.8 [5]. The rich-burn condition in this zone has a special advantage where it enhances the stability of the combustion reaction by producing and sustaining a high concentration of energetic hydrogen and hydrocarbon radical species, also the production of nitrogen oxides is less in case of rich-burn conditions due to the relative low temperatures and low population of oxygen containing intermediate species [12]. In the quick-quench stage, a large amount of air is introduced to mix quickly to complete the rapid transition from rich to lean burn, so as to prevent the area with large $\mathrm{NO}_{\mathrm{x}}$ production near the stoichiometric ratio [15], also this second process is very important because it leads to oxidise $\mathrm{CO}$, hydrogen and hydrocarbon intermediates, where the resulting gas from the first region (rich-burn) contains a high amount of CO, UHC and smoke that cannot be exhausted without further processing $[15,16]$. Finally, the Lean-burn region (typical equivalence ratio is in the range of 0.5-0.8), which is very important because it helps to achieve more $\mathrm{CO}$ and $\mathrm{UHC}$ consumption also for lower $\mathrm{NO}_{\mathrm{x}}$. The combustor outlet temperature distribution quality is controlled by this region.

\subsection{Lean Premixed Prevaporised combustors (LPP)}

A technology of reducing the combustion temperature of various fuels that has gained popularity in the past few decades is to mix fuel and air in fuel lean proportions before the combustible mixture reaches the combustion zone [18,19]. The fuel is vaporised and then mixed with the air flow to create a lean, homogeneous mixture before entering the combustion zone and burning at a low equivalence ratio that is close to the lean blowout limit, and due to the low flame temperature and the elimination 
of hot spots from the combustion zone a significant reduction in emission levels of nitrogen oxides. Basically, LPP combustor consists of three main sections, where the first is for fuel injection, vaporisation, and fuel-air mixing such that completed fuel evaporation and fuel-air mixing can be achieved, the second is for combustion where the flame is stabilised in the recirculation zones and the third may comprise a conventional dilution zone [5]. In the development of LPP combustors, the success of the LPP combustion process mainly depends on the flow field, evaporation characteristics of fuel spray and the fuel/air mixing in the combustion zone [20]. Combustor designs of this kind are very complex because they require sophisticated harde-ware for proper staging of the combustion process [1], where there are many challenges, among them the auto-ignition and flashback risk which become severe at higher OPR engines, this limits the further application for future gas turbines. Also Higher lean blowout risk due to ultra-lean burn and staged combustion has to be employed with compromise in higher production for $\mathrm{NO}_{\mathrm{x}}$ emission at engine part load [5].

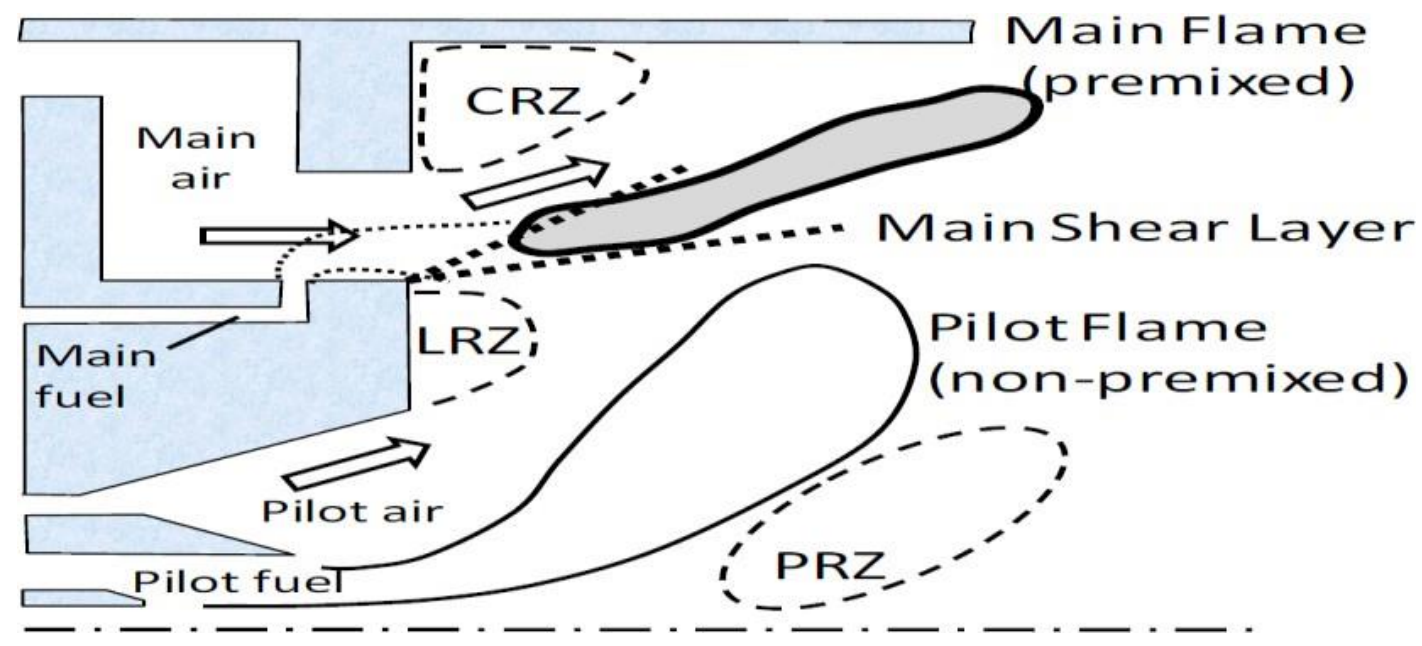

Figure 5. Schematic of the Flow Pattern in the Lean Premixed Prevaporized Combustor [21].

\subsection{Double Annular Combustors (DAC)}

Generally speaking, the original intent of DAC was to get $50 \% \mathrm{NO}_{\mathrm{x}}$ reduction over state of-the-art combustors introduced in the early 1970's, where the concept of this technology was first conceived by Bahr and Gleason [22,23]. These combustors are based on a radially staging strategy [5]. The combustion stoichiometry and hence temperature is controlled through the use of fuel injection in multiple combustion locations. At low power settings, part of combustion zones operates and refers to the pilot zone (i.e. the outer annulus) (Figure 6) to raise the equivalence ratio (around 0.8) so as to increase the combustion efficiency and reduce $\mathrm{CO}$ and UHC. The pilot zones which are represented by outer circumferentially arranged circles and red colour indicates the injectors are fuel filled and operating. The local high combustion stoichiometry also mitigates the risk of lean instability. At higher power settings, typically at approach condition, zones that are called main (i.e. the inner annulus) get fuelled and ignited. The equivalence ratios for both zones are usually kept at 0.6. The objective is to achieve lean combustion for $\mathrm{NO}_{\mathrm{x}}$ and smoke reduction at high power. During 
mid-power, part of the main zone is fuelled and operated, this aims to increase the transition efficiency and more than one staging point is employed [5].
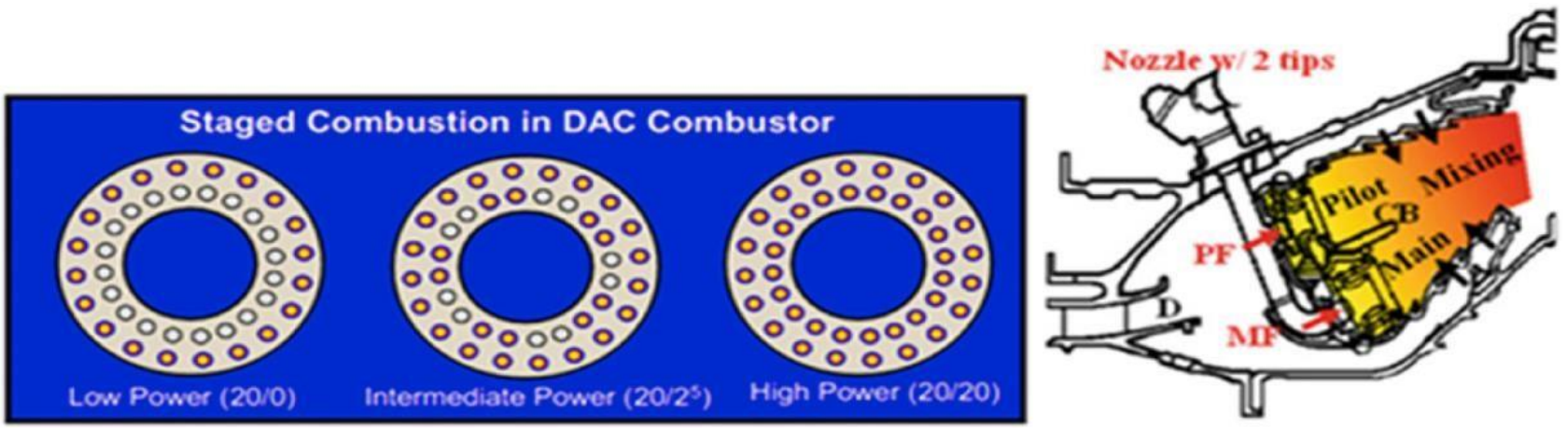

Figure 6. DAC working principles with fuel staging schemes: low power only outer annulus injectors operating, mid power outer + part of inner, full power outer + inner [5].

Studies have shown that DAC technology is competitive with rich dome combustors at lower OPRs for a trade-off between the $\mathrm{CO}$ and $\mathrm{NO}_{\mathrm{x}}$ emissions. However, higher $\mathrm{EL}_{\mathrm{CO}}$ and $\mathrm{EL}_{\mathrm{NOx}}$ are produced at increased engine OPRs. A higher $\mathrm{CO}$ emissions at idle is primarily due to quenching effect between the two combustion domes. The UHC emissions yield the similar trends and generally the smoke emissions for DAC are lower than RQL combustors with the overall level below 6 over the OPR ranges [5].

Many advantages are provided through the use of DAC technology, for example, the lean combustion is operated at high power providing the potential to reduce the $\mathrm{NO}_{\mathrm{x}}$ emissions. The commonly shared feed arm enables the pilot fuel to cool the main fuel, lowering the risks for fuel coking. There are many design challenges in DAC technology, for example the excessive mission fuel burn due to the radial profile design challenge, control of pattern factor and turbine transverse quality, challenges in cooling due to lager dome surface areas and unfavorable transition combustion efficiency in the mid power range [5].

\subsection{Twin Annular Premixing Swirler combustors (TAPS)}

The TAPS combustor evolved based on lessons learned with fuel staging of the DAC, and also benefitted from extensive experience with Dry Low Emissions lean premixing combustors in aeroderivative industrial gas turbines [24]. It is a premixing main swirler built concentrically around the well-proven swirl cup mixer, and hence the use of the word twin [23]. The TAPS combustor concept is a lean burn system where each fuel injector contains a center pilot and concentric outer main as shown in Figure 7. The central pilot tip is a rich burn configuration similar to traditional combustors. At starting and low power operation fuel is $100 \%$ in the pilot. At higher power fuel is split between the pilot and main. The main injection is a set of radial jets that enter a larger main air swirler. The main is a large effective area swirler to burn fuel lean. At high power most of the fuel is injected through the main. This makes both the pilot and main mixers fuel lean with approximately $70 \%$ of combustor total air flow through those 2 mixers [25]. 

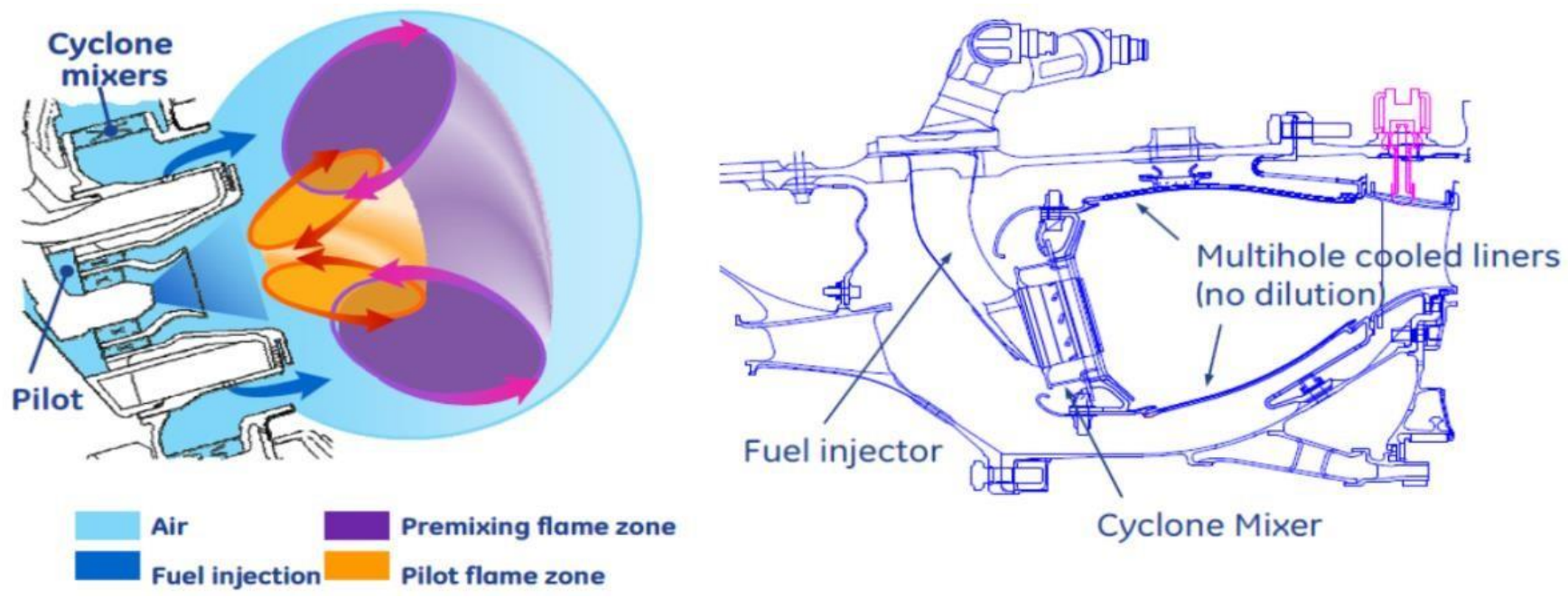

Figure 7. TAPS mixer concept and GEnx TAPS I cross section [26].

This technology has shown many advantages, among these advantages: ultra-low $\mathrm{NO}_{\mathrm{x}}$ emissions due to premixed combustion demonstrate the potential in achieving long term $\mathrm{NO}_{\mathrm{x}}$ goals (TAPS III technology has achieved $75 \%$ reduction relative to CAEP/6). Improved combustor exit temperature distribution due to internally stage configuration, where this enhances the turbine life and reduces the mission fuel burn. Improved liner structural integrity due to elimination of the large dilution holes that cause the local stress concentration and the advanced fuel nozzle manufacturing technology enables the complex fuel nozzle system to be applied in the further application [5].

\subsection{Axially Staged Combustors (ASC)}

ASC concept was conceived roughly in the same timeframe as DAC in the 1970s. It was developed by Pratt \& Whitney in the NASA Experimental Clean Combustor Program ECCP. The working principle of ASC combustors is similar to the DAC, but fuel staging is achieved through the fuel injection zones placed in the axial direction. The main stage is placed downstream of the combustor, and the pilot zone is placed at the upstream (Figure 8). Axial staging does have certain advantages over radial staging. Since the main stage is downstream of the pilot stage, ignition of the main stage directly from the pilot is both rapid and reliable. Also, the hot gas flow from the pilot into the main combustion zone ensures high combustion efficiency from the main stage, even at low equivalence ratios [27]. The P\&W team chose the Axially Controlled Stoichiometry (ACS) as a term in the current development to express the ASC technology. The arrangement of the separation of the pilot and the main provides for efficiency and stability at low power, and stability at all operating conditions. Mixing of the pilot and main is controllable according to PW experience. P\&W has experience in the design and manufacture of ASC systems due to the V2500 design. The ASC distributes the heat release axially, reducing susceptibility to acoustics [28]. One of the main advantages of this technology is the lower level of $\mathrm{NO}_{\mathrm{X}}$ at high power that can be achieved for reduced residence time since the main stage can burn efficiently. 


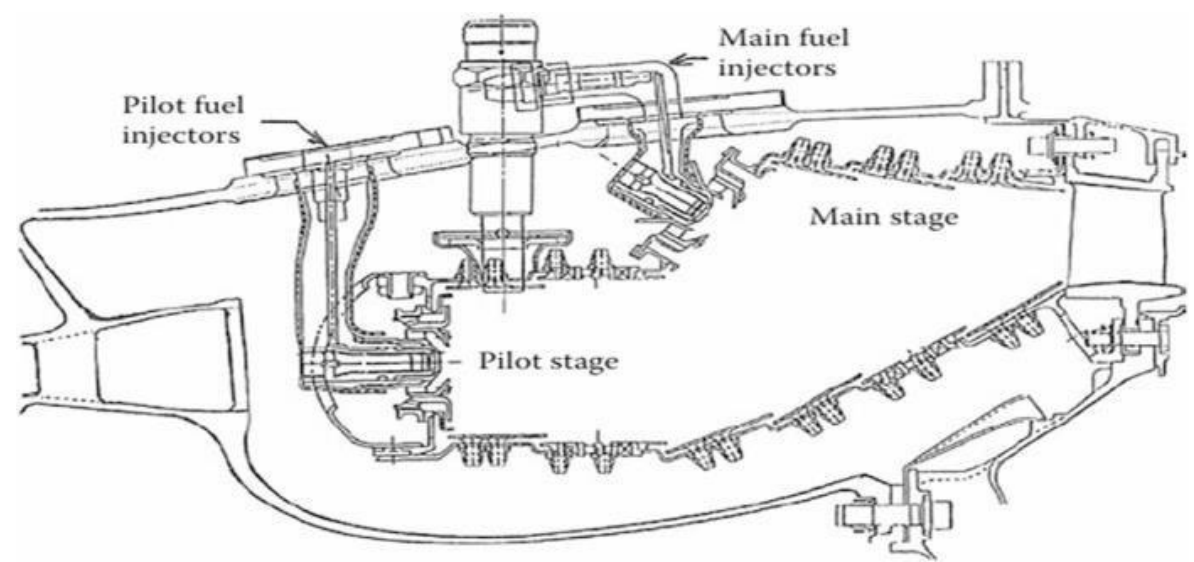

Figure 8. Pratt and Whitney axially staged combustor [27].

The results of tests performed on ACS combustor showed that the efficiency was above $99.9 \%$ at all fully staged high power points. Cruise $\mathrm{NO}_{\mathrm{x}}$ levels were $2 \mathrm{EI}$ and below. Also emissions were measured idle, take- off, climb, and approach, and a $\mathrm{NO}_{\mathrm{x}}$ EPAP of $88 \%$ below CAEP/ 6 was calculated using an $\mathrm{N}+2$ cycles based on an advanced Geared Turbo Fan [28].

\subsection{Variable Geometry Combustors (VGC)}

Variable geometry combustor is an unconventional method of reducing engine emissions and increasing combustion efficiency based on the active distribution of air among the individual combustor zones [29]. This technology provides the flexibility to control the airflow distribution inside a combustor and therefore has the ability to reduce the emissions on both high and low operating conditions without losing combustor performance. It also has a great potential to improve combustion efficiency at low power operating conditions, and facilitate engine relight at altitude [30].

The air flow splitter is driven by a hydraulic system and is allowed translational movement (moves forward and backwards) to vary the cross-sectional area and hence the air flow ratio into the primary zone. At lower power conditions, the degree of opening of the splitter increases the quantity of air diverted backwards to create a high primary Fuel Air Ratio FAR and a reducing flow velocity for high combustion efficiency and improved stability, as well as good light-up capability. As power is increased, the splitter opens, introducing more air into the primary zone to achieve low FAR such that lean combustion is achieved for the purpose of $\mathrm{NO}_{\mathrm{x}}$ and smoke reduction [5].

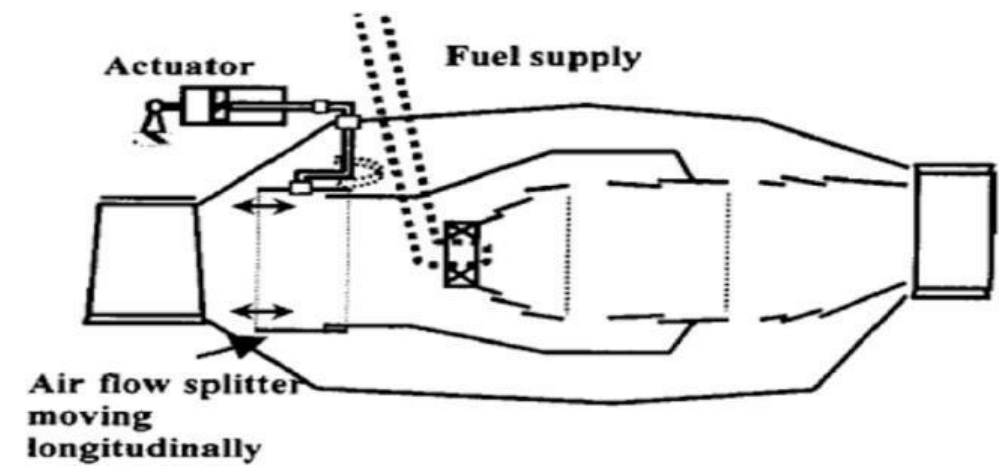

Figure 9. The variable geometry combustor concept schematics [31]. 
The design of VGC technology involves difficulties and challenges. For example increased weight due to the introduction of a control system is a significant challenge for aero applications, complexity of control system and the high cost and liner durability challenge arises from the cooling flow distortion in combustor annulus passage.

\subsection{Lean Direct Injection combustors (LDI)}

Lean combustion in gas turbine combustors is fast becoming the norm due to environmental and efficiency concerns. A promising design is the lean direct injection (LDI) [32]. It has been of active interest due to its potential for low emissions under operational (high-temperature, high pressure) conditions [33]. In this technology, the liquid fuel is injected from a venturi directly into the incoming swirling airstream, and the swirling airflow is used both for atomizing the injected liquid and for fuelair mixing. Autoignition and/or flashback are minimized since the fuel neither premixed nor prevaporized [34].

\section{Conclusion}

The current technologies used in aero gas turbine engines show very good results in reducing emissions of pollutants, but the updated regulations which control the aviation emissions include more stringent standards this leads to motivate the researchers and the manufacturers to improve these technologies by issuing new versions and/or creating new technologies with new concepts. For this reason there is a remarkable and continuous development in this research field.

\section{Acknowledgments}

The described article was carried out as part of the EFOP-3.6.1-16-2016-00011 "Younger and Renewing University - Innovative Knowledge City - institutional development of the University of Miskolc aiming at intelligent specialization" project implemented in the framework of the Széchenyi 2020 program. The realization of this project is supported by the European Union, co-financed by the European Social Fund.

\section{References}

[1] F. Ommi - M. Azimi (2012) Most effective combustion technologies for reducing NOX emissions in aero gas turbines. Int. Jnl. of Multiphysics. 6 (4)

[2] Introduction: Aviation Outlook ICAO Environmental Report, 2010

[3] World Bank Group, Pollution Prevention and Abatement Handbook, 1998: Toward Cleaner Production, World Bank Publications, 1999, ISBN 082133638X, 9780821336380, 231

[4] H.C. Mongia - W.G.A.E. Dodds (2004) Low emissions propulsion engine combustor technology evolution past, present and future, in: 24th Congress of International Council of the Aeronautical Sciences, Yokohama, Japan. 
International Journal of Engineering and Management Sciences (IJEMS) Vol. 4. (2019). No. 1

DOI: 10.21791/IJEMS.2019.1.62.

[5] Y. Liu - X. Sun - V. Sethi - D. Nalianda - Y. Li - L. Wang (2017) Review of modern low emissions combustion technologies for aero gas turbine engines. Progress in Aerospace Sciences 94 pp. 12$45-$

[6] F. M. Matias (2016) Turbofan Engine Optimization for Low NOX Emissions, Thesis.

[7] Environment Branch of the International Civil Aviation Organization (ICAO), ICAO Environmental Report 2016, Technical report, ICAO, 2016

[8] N. Dickson (2014) Local Air Quality and ICAO Engine Emissions Standards. Available at: http://www.icao.int/Meetings/EnvironmentalWorkshops/Documents/2014Kenya/41_LAQTechnology_notes.pdf

[9] I. Secretariat (2013) Aircraft technology improvements, ICAO Environmental Report.

[10] P. Madden (2014) CAEP Combustion Technology Review Process and CAEP NOX Goals, Rolls Royce,

[11] [M.R.J. Charest - J.E.D. Gauthier - X. Huang (2006) Design of Lean Premixed Prevaporised can combustor, ASME Turbo Expo 2006: Power for Land, Sea and Air, 2

[12] S. Samuelsen: 3.2.1.3 Rich Burn, Quick-Mix, Lean Burn (RQL) Combustor, pp. 227-228

[13] G.S. Samuelsen, et al. (2013) Experimental and modeling investigation of the effect of air preheat on the formation of NOx in an RQL combustor, Heat Mass Transf. 49 (2) pp. 219-231.

[14] B. Ge - Y. Gi - S. Zang - Y, Yuan - J. Xian (2016) Investigation of the combustion performance in a three- nozzle RQL combustor, Proceedings of ASME Turbo Expo 2016: Turbomachinery Technical Conference and Exposition

[15] J. Chen - J. Li - L. Yuan - G. Hu (2018) Flow and flame characteristics of a RP-3 fuelled high temperature rise combustor based on RQL, Elsevier.

[16] G.S. Samuelsen, et al. (2013) Experimental and modeling investigation of the effect of air preheat on the formation of NOx in an RQL combustor, Heat Mass Transf. 49 (2)

[17] A. Innocenti (2015) Numerical analysis of the dynamic response of practical gaseous and liquid fuelled flames for heavy-duty and aero-engine gas turbines, $\mathrm{PhD}$ thesis, Universita degli Studi di Firenze.

[18] T. Ikezaki - J. Hosoi - T. Hidemi (2001) The performance of the low Nox aero gas turbine combustor under high pressure, ASME, 2001-GT-0084.

[19] A.H. Lefebvre (1997) Lean Premixed/Prevaporized Combustion, A workshop held at Lewis Research Center Cleveland, Ohio, NASA CP-2016.

[20] Y. Yan - Y. Wang - Y.Deng - J. Li (2016) Fuel spray characteristics investigation in LPP combustor. Aircraft Engineering and Aerospace Technology: An International Journal. 88 (4) pp. 498-507.

[21] J. E. Temme - P.M. Allison - J. F. Driscoll (2012) Low Frequency Combustion Instabilities Imaged in a GasTurbine Combustor Flame Tube, the American Institute of Aeronautics and Astronautics.

[22] D.W. Bahr - C.C. Gleason (1973) Experimental Clean Combustor Program, Phase I-final Report, NASACR-134737.

[23] H. Mongia - W. Dodds: Low Emissions Propulsion Engine Combustor Technology Evolution Past, Present and Future, GE Aircraft Engines, Cincinnati, Ohio, U.S.A, 1-7

[24] G. Leonard - J. Stegmaier (1994) Development of an Aeroderivative Gas Turbine Dry Low Emissions Combustion System, J. Eng. Gas Turbines Power. 116 (3) p. 542.

[25] General Electric, TAPS II Combustor Final Report, Continuous Lower Energy, Emissions and Noise(CLEEN) Program, June, 2013 
[26] J. Herbon - J. Aicholtz - S.Y. Hsieh and others (2017) N+2 Advanced Low NOx Combustor Technology Final Report, NASA/CR-2017-219410. pp. 1-120

[27] A.H. Lefebvre - D.R. Ballal (2010) Gas Turbine Combustion: Alternative Fuels and Emissions, third ed, Taylor \& Francis.

[28] C. M. Lee - C. Chang (2013) NASA project develops next generation low-emissions combustor technologies, 51st AIAA Aerospace Sciences Meeting Including the New Horizons Forum and Aerospace Exposition, 2013, Texas

[29] M. Chmielewski - M. Gieras (2016) Impact of variable geometry combustor on performance and emissions from miniature gas turbine engine, Elsevier.

[30] Y. G. Li - R. L. Hales (2003) Steady and Dynamic Performance and Emissions of a Variable Geometry Combustor in a Gas Turbine Engine. Journal of Engineering for Gas Turbines and Power. 125 pp. 961-971.

[31] Y.G. Li - R.L. Hales: Gas Turbine Emissions Control Using Variable Geometry Combustor and Fuel Staging, AIAA, 2002-0079

[32] N. Patel - M. Kirtas - V. Sankaran - S. Menon (2007) Simulation of spray combustion in a leandirect injection combustor. Elsevier, Proceedings of the Combustion Institute. 31 pp. 2327-2334.

[33] N. Patel - S. Menon (2008) Simulation of spray-turbulence-flame interactions in a lean direct injection combustor. Elsevier, Combustion and Flame. 153 pp. 228-257.

[34] R. Tacina - C. Wey - P. Laing - A. Mansour (2002) NASA Technical Memorandum, NASA TM2002- 211347. 